\title{
Characteristics of hepatitis viruses among Egyptian children with acute hepatitis
}

\author{
AHMED YOUSSEF $^{1}$, YOSHIHIKO YANO $^{1,2}$, MAYSAA EL-SAYED ZAKI $^{3}$, \\ TAKAKO UTSUMI $^{1,4}$ and YOSHITAKE HAYASHI ${ }^{1}$
}

\begin{abstract}
${ }^{1}$ Center for Infectious Diseases, ${ }^{2}$ Department of Gastroenterology, Kobe University Graduate School of Medicine, Kobe, Japan; ${ }^{3}$ Department of Clinical Pathology, Faculty of Medicine, Mansoura University, Mansoura, Egypt;

${ }^{4}$ Indonesia-Japan Collaborative Research Center for Emerging and Re-emerging Infectious Diseases, Institute of Tropical Disease, Airlangga University, Surabaya, Indonesia
\end{abstract}

Received November 21, 2012; Accepted January 18, 2013

DOI: $10.3892 /$ ijo.2013.1822

\begin{abstract}
Hepatitis viral infection is hyperendemic in Egypt, western Asia and Africa. However, little is known about the status of hepatitis viruses among rural Egyptian children. Therefore, this study sought to examine the prevalence and characteristics of hepatitis viruses among symptomatic Egyptian children. Serological and molecular analyses of hepatitis viral infection were conducted in 33 children hospitalised at Mansoura University with symptomatic hepatic dysfunction (mean \pm standard deviation age, $9.7 \pm 3.4$ years; alanine aminotransferase level, $130 \pm 68 \mathrm{IU} / \mathrm{ml})$. Eleven children (33\%) were positive for anti-haemagglutination-IgM and were diagnosed with acute hepatitis A. Hepatitis B surface antigen (HBsAg) and anti-hepatitis $\mathrm{C}$ virus (HCV) were detected in $9(27 \%)$ and $7(21 \%)$ children, respectively, indicating acute-on-chronic infection with hepatitis viruses. None of the children was positive for anti-hepatitis B core antigen-IgM. Phylogenetic analysis confirmed that all HBVs belonged to genotype D (subgenotype D1) and that HCV belonged to genotypes $4 \mathrm{a}$ and $1 \mathrm{~g}$. HBV-DNA was detected in 9 children $(27 \%)$ in the pre-S/S region and in 16 children $(48 \%)$ in the core promoter/precore region. The Y134F amino acid mutation in the ' $\alpha$ ' determinant region was detected in all of the patients. The A1762T/G1764A double mutation, and the T1846A and G1896A single mutations were common in children with occult HBV infection. In conclusion, hepatitis viral infection, including acute-on-chronic infection with $\mathrm{HCV}$ and $\mathrm{HBV}$, is common in Egyptian children hospitalised with acute hepatitis.
\end{abstract}

\section{Introduction}

Hepatitis virus infection is a major global health problem. Acute hepatitis is sometimes serious and may be fatal in children

Correspondence to: Dr Yoshihiko Yano, Center for Infectious Diseases (CID), Kobe University Graduate School of Medicine, 7-5-1 Kusunoki-cho, Chuo-ku, Kobe 650-0017, Japan

E-mail: yanoyo@med.kobe-u.ac.jp

Key words: hepatitis virus, acute hepatitis, children, Egypt because of their immature immune system. Egypt has one of the highest prevalence rates of hepatitis $\mathrm{C}$ virus (HCV) infection owing to the vigorous public health campaigns conducted between the 1950s and 1982 to eradicate schistosomiasis (1). Hepatitis B virus (HBV)-related liver disease is also common in Egypt, like many other countries. Consequently, Egyptian children are at particularly high risk of $\mathrm{HBV}$ and $\mathrm{HCV}$ infection.

Egypt was one of the first countries to introduce universal HBV vaccination in 1992. The Ministry of Health and Population conducted a wide range of prophylactic strategies to control viral hepatitis. It was reported that the prevalence of hepatitis B surface antigen (HBsAg) positivity among healthy individuals decreased from $10.1 \%$ in 1985 to $1.18 \%$ in 2008, and the frequency of acute HBV infection as a cause of symptomatic hepatitis decreased significantly from $43.4 \%$ in 1983 to $28.5 \%$ in 2002 (2-4). Hepatitis virus infection, particularly HCV infection, was reported to be an important risk factor for acute hepatitis in Egyptian children (5). In Africa, acute hepatitis is still common and is sometimes fatal. However, the reason for this is unclear, and may be related to coinfection with Leptospira or Rift Valley fever virus, for example $(6,7)$.

Hepatitis A virus (HAV) is also an important pathogen that is frequently associated with acute hepatitis. An Egyptian earlier survey examined more than 5,000 patients with acute hepatitis and showed that $40.2 \%$ of patients had HAV-related acute hepatitis (8). In addition, $94.4 \%$ of children aged $>5$ years were reportedly positive for anti-HAV IgG (9). These findings also suggest that most Egyptian children were exposed to HAV in their childhood.

In this study, we analysed the aetiology of hepatitis virus using serological and genetic methods in 33 Egyptian children hospitalised with acute hepatitis.

\section{Materials and methods}

Study subjects. This study was conducted at the Children's Hospital, Mansoura University, Mansoura, Egypt. Thirty-three children with acute hepatitis were identified and included in the study. The study subjects were mostly male $(n=26)$, with a mean \pm standard deviation (SD) age of $9.7 \pm 3.4$ years. Overall, 
$60.6 \%$ of the children lived in rural areas. All of the children enrolled in the study underwent thorough clinical examinations and their medical history was carefully reviewed. Acute hepatitis is defined as acute hepatic injury, manifested by the release of cytoplasmic enzymes, particularly alanine aminotransferase (ALT) and aspartate aminotransferase (AST). In three of the patients, with mean ALT, AST and total bilirubin (T-Bil) levels of $130.1 \pm 68.3 \mathrm{IU} / 1,146 \pm 68.3 \mathrm{IU} / 1$ and $2.9 \pm 1.2 \mathrm{mg} / \mathrm{dl}$, respectively, increases in these enzymes was accompanied by symptoms such as fever, loss of appetite, abnormal bilirubin metabolism-related jaundice, dark urine and pale stools. All of the patients had AST and ALT levels over two times the upper limit of normal at acute onset. Informed written consent was obtained from the parents of all the children. The study was approved by the Ethics Committee of Mansoura University.

Serological markers of HBV infection. HBsAg was assessed using a reversed passive hemagglutination (R-PHA) test (Mycell II HBsAg; Institute of Immunology, Tokyo, Japan). Anti-HCV antibody (HCV-Ab) was examined using the passive Ortho HCV-Ab PA Test II (Fujirebio Inc., Tokyo, Japan). Anti-hemagglutination (HA)-IgM, anti-hepatitis B surface (HBs) and anti-hepatitis B core antigen ( $\mathrm{HBc}$ )- $\operatorname{IgM}$ antibodies were assessed using radioimmunoassays (SRL Inc., Tokyo, Japan). Laboratory investigations, including liver function tests, were performed using a Synchron autoanalyser (Beckman Coulter, Fullerton, CA, USA). ALT, AST, albumin and T-Bil levels were measured in all serum samples.

$D N A / R N A$ extraction and viral load of $H B V$. Viral DNA was extracted from $200 \mu \mathrm{l}$ of serum using a QIAamp DNA Blood mini kit and a QIAamp viral RNA kit (Qiagen GmbH, Hilden, Germany), following the manufacturer's instructions. The viral load was assessed by real-time PCR using an ABI Prism 7700 analyser (Applied Biosystems, Foster City, CA, USA). HBV was amplified with a primer and probe set, as previously described (10).

Amplification of the HBV/HCV genome and identification of mutations. The sequence of the core promoter/precore (CP/PC) region was amplified by PCR with nested primers (11). The amplified fragments were directly sequenced and the $\mathrm{G} \rightarrow \mathrm{A}$ substitution at nucleotide (nt) 1,896 in the $\mathrm{PC}, \mathrm{A} \rightarrow \mathrm{T}$ at nt 1,762 , $\mathrm{G} \rightarrow \mathrm{A}$ at $\mathrm{nt}$ 1,764 in the basal $\mathrm{CP}$, and the Kozak sequence (CCACC; nt 1,809-1,813) were analysed.

The complete nucleotide sequences of HBV from two samples were sequenced using two overlapping amplicons with specific primers (12). A second PCR was performed to detect the full genome sequence in two virus isolates and for pre-S1/S2/S gene detection using the previously reported primers and PCR conditions (13).

The extracted RNA was reverse-transcribed to cDNA using a Sensiscript RT kit (Qiagen $\mathrm{GmbH}$ ) with oligo dT primers (Promega, Madison, WI, USA). The transcribed cDNA was used for HCV amplification by nested PCR. The 5'-non-coding regions of HCV-RNA were amplified $(14,15)$.

Genotyping of hepatitis virus by phylogenetic analysis. The amplified products of the second PCR were directly sequenced
Table I. Serological and clinical characteristics of the patients.

\begin{tabular}{lccc}
\hline & HA-IgM & HBsAg & anti-HCV \\
\hline Positive number (\%) & $11(33 \%)$ & $9(27 \%)$ & $7(21 \%)$ \\
Male/female & $8 / 3$ & $7 / 2$ & $5 / 2$ \\
Age (years) & $8.0 \pm 3.3$ & $10.8 \pm 2.9$ & $9.3 \pm 3.6$ \\
ALT (IU/l) & $137 \pm 89$ & $134 \pm 34$ & $131 \pm 64$ \\
T-Bil (mg/dl) & $3.0 \pm 1.2$ & $2.8 \pm 1.0$ & $2.0 \pm 0.4$ \\
\hline
\end{tabular}

using the Taq Dye Deoxy Terminator cycle sequencing kit with a 3100-Avant genetic analyser (Applied Biosystems).

The two full-genome and $\mathrm{S}$ gene sequences of the HBV strains determined in this study were compared with those of 20 reference sequences retrieved from the DDBJ/EMBL/GenBank database. The subtypes of the strains used for comparison were obtained from published articles (16).

The sequences were aligned using CLUSTAL X software and the phylogenetic trees were constructed by the neighbourjoining method (17). To confirm the reliability of the phylogenetic tree analysis, bootstrap resampling and reconstruction were carried out 1,000 times. These analyses were conducted using the Molecular Evolutionary Genetics Analysis (MEGA) software program (available at http://www.megasoftware.net) (18).

\section{Results}

Serologicalmarkers andlaboratory characteristics. Serological data are summarized in Table I. Overall, 11 (33\%) and 7 (21\%) children were positive for HA-IgM and anti-HCV antibodies, respectively. HBsAg was detected in 9 children (27\%) while the other $24(73 \%)$ were negative. There were no significant clinical differences among children according to the type of hepatitis. Of the HBsAg-positive children, one (case 4) was coinfected with HAV and three (cases 9, 16 and 19) had $\mathrm{HCV}$. On the other hand, only three children were positive for anti-HBs antibodies and none was positive for anti-HBc-IgM antibodies. HBV-DNA corresponding to the pre-S/S and CP/ $\mathrm{PC}$ regions was detected in all nine $\mathrm{HBs} A g$-positive children. $\mathrm{HBV}$-DNA corresponding to the $\mathrm{CP} / \mathrm{PC}$ region was detected in $7 / 24 \mathrm{HBsAg-negative} \mathrm{children.} \mathrm{There} \mathrm{were} \mathrm{no} \mathrm{clinical}$ differences between the HBsAg-positive and HBsAg-negative children (Table II).

$C P / P C$ mutations. Mutations in the pre-S/S and $\mathrm{CP} / \mathrm{PC}$ regions were detected by the PCR-direct sequencing method. All of the children, except for cases 22 and 24, were double-wild for the A1762T/G1764A double mutation. The G1896A mutation was found in 3/7 (43\%) HBsAg-negative children, compared with just 1/9 (11\%) HBsAg-positive children. No specific mutations were found in $\mathrm{C} 1653$, T1753 or T1858.

Sequencing and phylogenetic analysis of the pre-S/S gene. The entire pre-S/S gene was sequenced in the nine $\mathrm{HBsAg}$-positive children and was converted to the corresponding amino acid sequence to identify amino acid variations. Fig. 1 summarises the amino acid mutations/variations in the pre-S/S region. While A79T was found in the pre-S region in one child (case 9), the 
Table II. Prevalence and characteristics of HBV carriers.

\begin{tabular}{lcccc}
\hline & \multicolumn{2}{c}{ HBV-DNA(+) } & & \\
\cline { 2 - 3 } & $\operatorname{HBsAg}(+)$ & HBsAg(-) & HBV-DNA(-) & Total \\
\hline Positive number (\%) & $9(27 \%)$ & $7(21 \%)$ & $17(52 \%)$ & 33 \\
Age (years) & $10.8 \pm 2.9$ & $9.1 \pm 3.7$ & $9.4 \pm 3.5$ & $9.7 \pm 3.4$ \\
Gender (male/female) & $7 / 2$ & $7 / 0$ & $12 / 5$ & $26 / 7$ \\
Residence (rural/urban) & $5 / 4$ & $5 / 2$ & $10 / 9$ & $20 / 13$ \\
ALT (IU/l) & $134.4 \pm 34.7$ & $127.9 \pm 47.6$ & $128.9 \pm 88.6$ & $130.2 \pm 68.3$ \\
T-Bil (mg/dl) & $2.8 \pm 1.0$ & $2.3 \pm 0.8$ & $3.2 \pm 1.4$ & $2.9 \pm 1.2$ \\
\hline
\end{tabular}

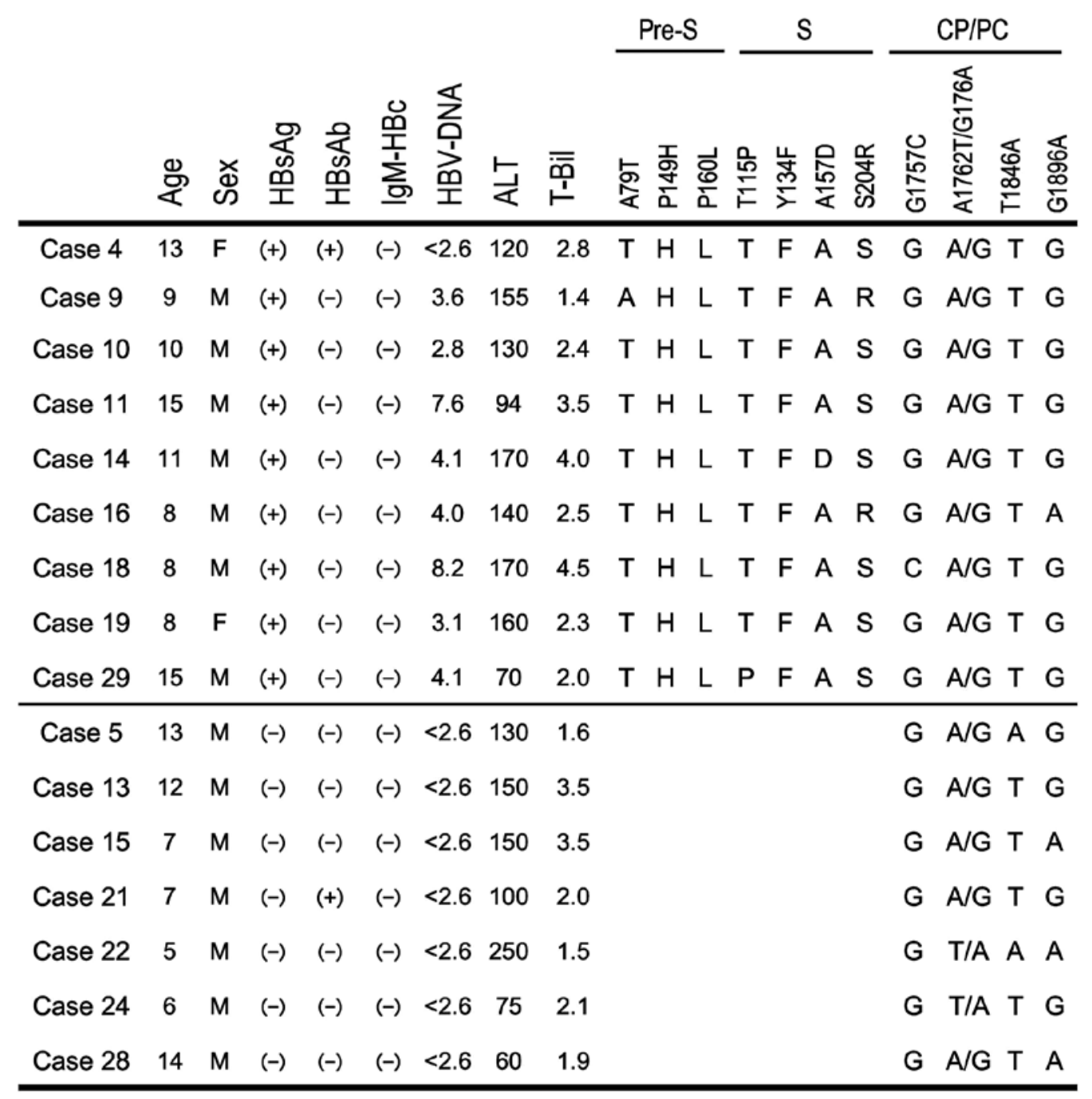

Figure 1. Clinical data and mutations/variations in the pre-S/S and CP/PC regions of HBsAg-positive and occult HBV cases. The P149H and P160L variants in the pre-S region and the $\mathrm{Y} 134 \mathrm{~F}$ variant in the ' $\alpha$ ' determinant region were detected in all of the children. A1762T/G1764A double mutations in the CP/PC region were detected in cases 22 and 24 .

P149H and P160L variants were found in all of the children. The T115P and A157D mutations were detected in one child and S204R mutation was detected two children in the S region.
The Y134F mutation in the ' $\alpha$ ' determinant region was identified in all of the children, but no specific mutations, such as T131I, K141E or G145R, were found in the $\alpha$ loop (amino acids 111-156). 


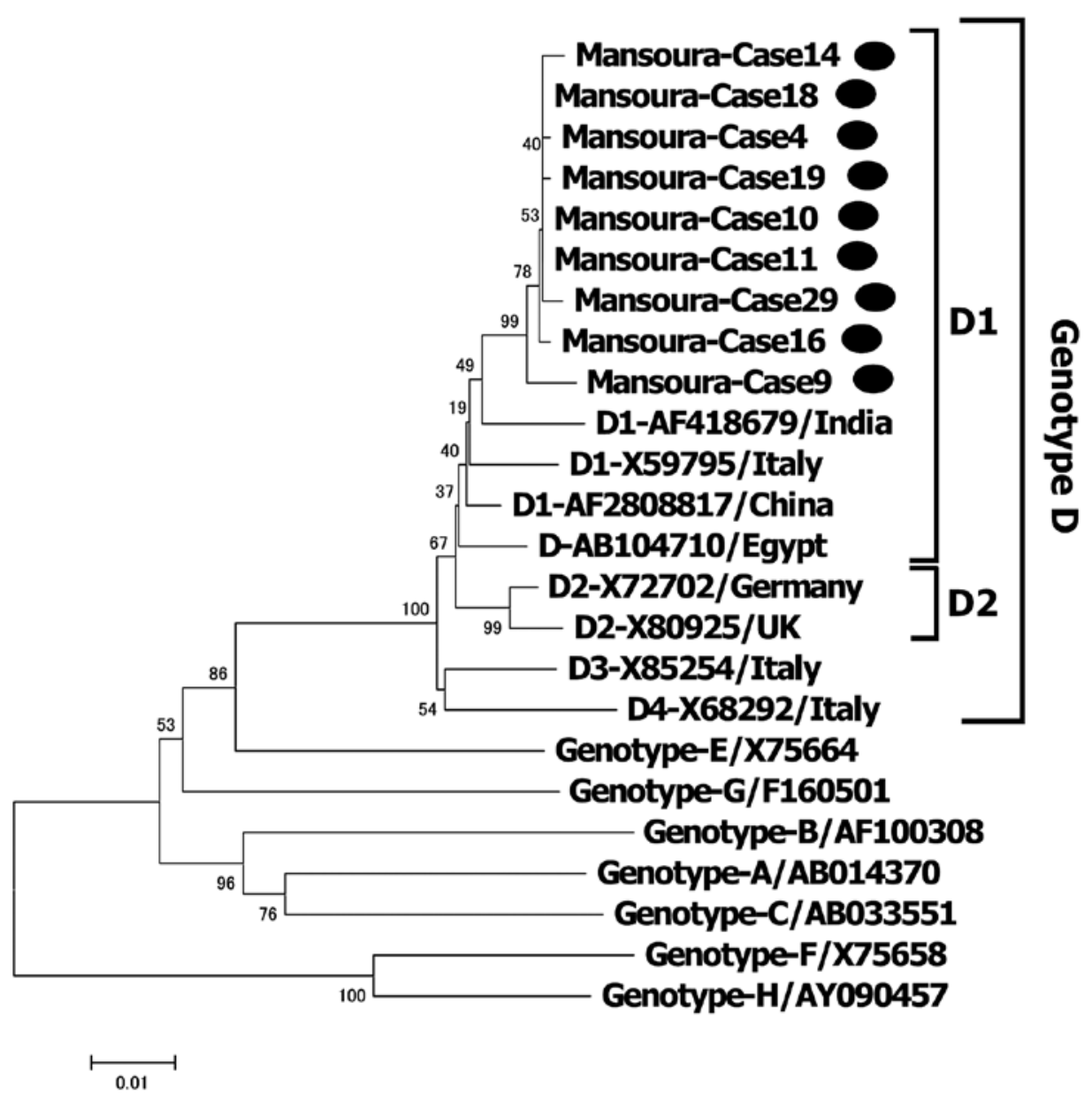

Figure 2. Phylogenetic analysis of the nine HBsAg-positive strains based on the pre-S/S region. A phylogenetic tree was constructed using 15 reference strains. The accession numbers and country of origin are indicated for the reference isolates. The length of the horizontal bars indicates the number of nt substitutions per site.

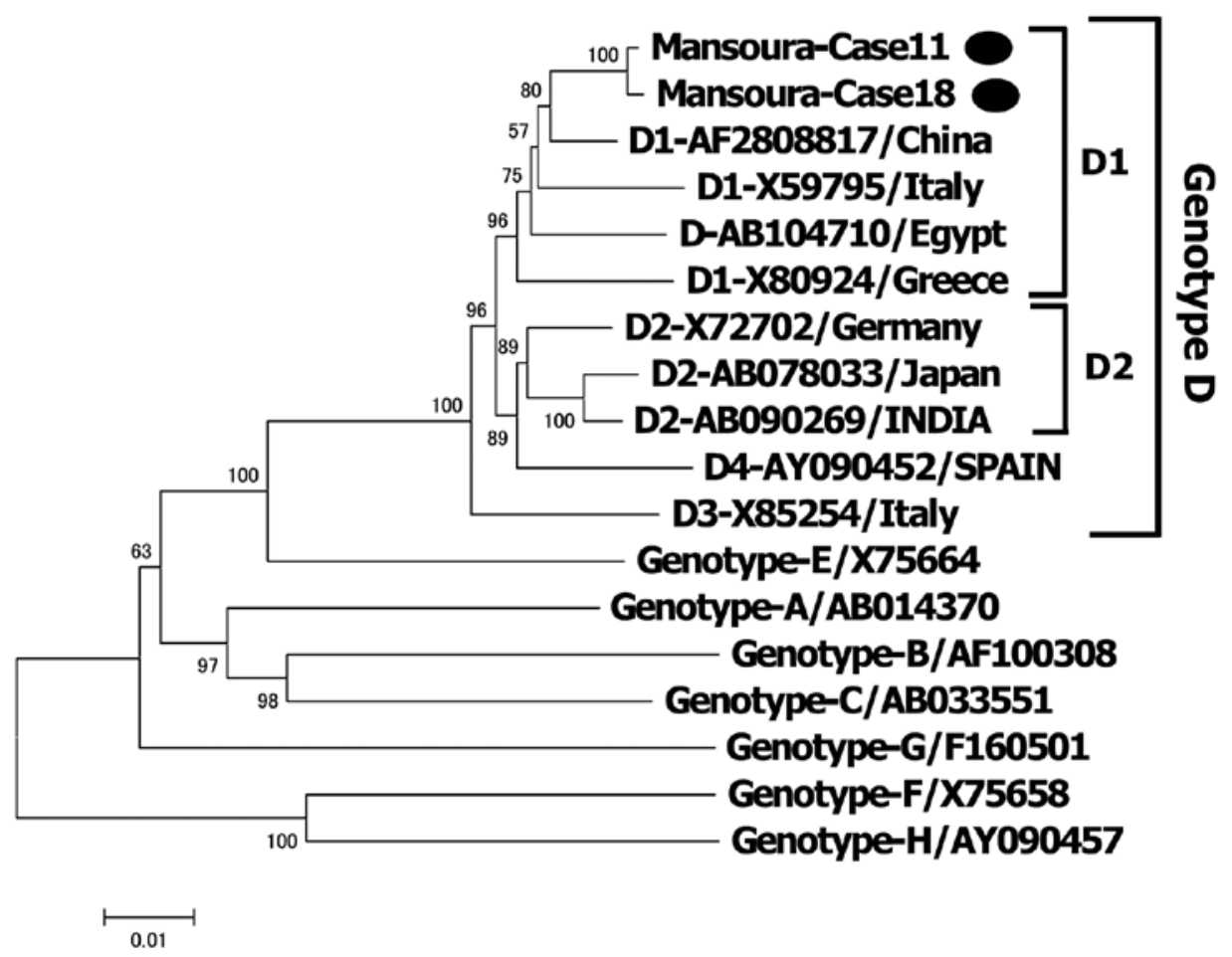




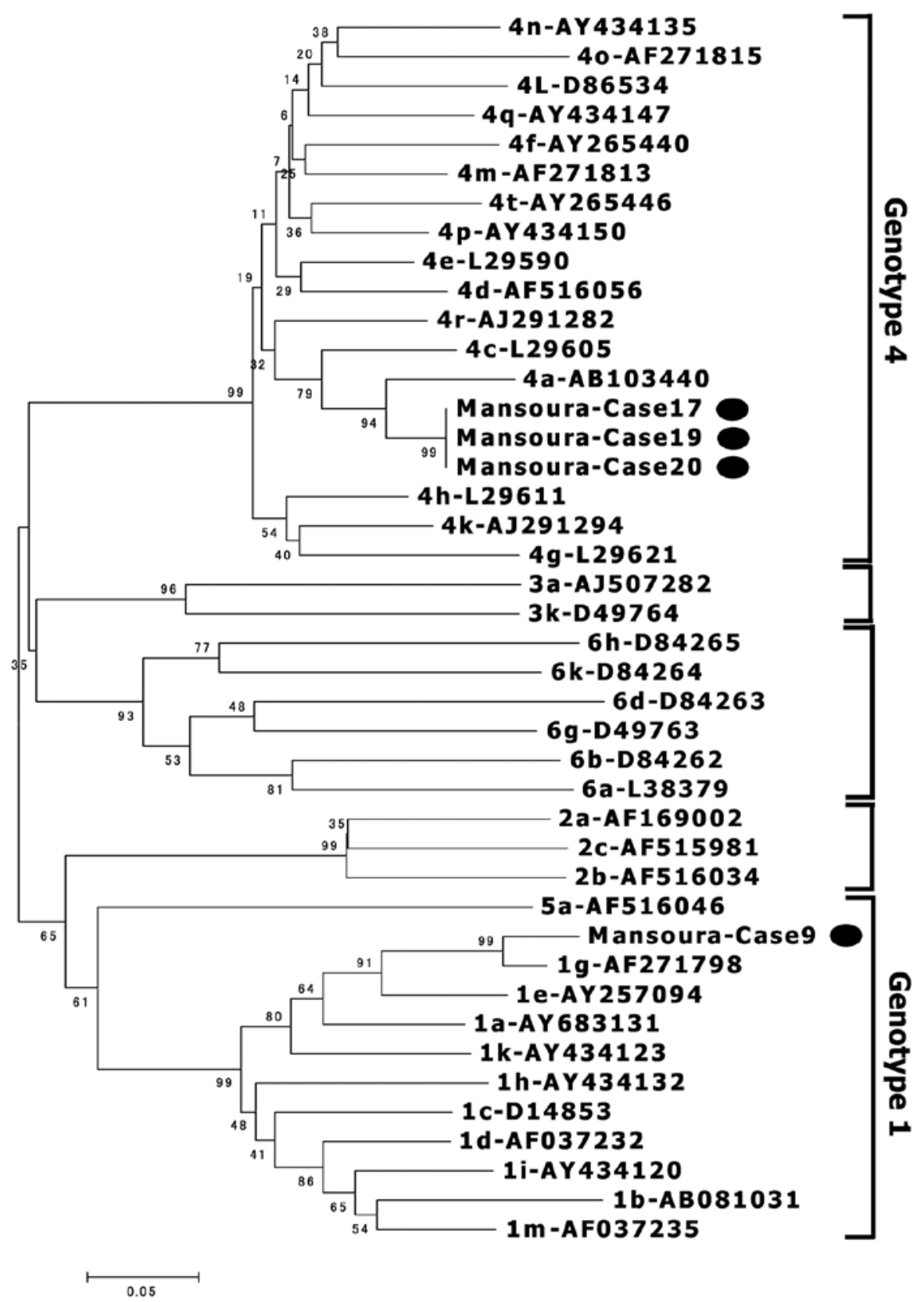

Figure 4. Phylogenetic analysis of four anti-HCV antibody-positive strains based on the NS5a region. Three genotypes were classified as subgenotype 4a and one was classified as subgenotype $1 \mathrm{~g}$.

A phylogenetic tree was constructed for the 9 children using 15 reference sequences of HBV isolates from various countries. HBV was classified as genotype D1 in all of the children (Fig. 2).

$H B V$ genotypes and complete nucleotide sequence of $H B V$. To confirm the genotyping, a phylogenetic tree was constructed using two complete genome sequences with 16 reference sequences of HBV isolates derived from various countries. The two complete genomes were 3,182 bp long with a common deletion of 33 nucleotides in the pre-S1 region. Both genotypes were classified as genotype D (subgenotype D1) (Fig. 3).

Detection of HCV-RNA and phylogenetic analysis. HCV-RNA was detected in $4 / 7$ children with anti-HCV antibodies.
The HCV genomes from four children were amplified and sequenced, and three were classified as subgenotype $4 \mathrm{a}$ and one as subgenotype $1 \mathrm{~g}$ (Fig. 4).

\section{Discussion}

The cause of acute hepatitis usually shows geographic differences. In particular, environmental factors (e.g., aflatoxin) and endemic infections (e.g., schistotomiasis) are associated with acute and chronic liver diseases in Egypt (19). Regarding viral hepatitis, it was reported that HCV infection is an important predictor of acute hepatitis among Egyptian children (5). Although HCV infection was relatively common, HAV infection was more prevalent in this study. Although the seroprevalence 
of HAV in children is associated with socioeconomic status in Egypt, the location of Mansoura may also partly explain the high prevalence in this study (20). El Mansoura is a city in Egypt with a population of 420,000. It is the capital of the Ad-Daqahliyah Governate. Mansoura lies on the east bank of the Damietta branch of the River Nile, in the delta region, about $120 \mathrm{~km}$ northeast of Cairo. Acute HAV infection is usually curable and its clinical course differs from those of HBV and HCV infections. This also explains why long-term follow-up is necessary for HBV and HCV infections.

HBV infection is a significant global health problem and may cause both acute and chronic infection in humans (21). The World Health Organization recently estimated that there are at least 350 million individuals worldwide with HBV infection (22). Infection with HBV can lead to progressive liver disease, including liver cirrhosis and hepatocellular carcinoma (HCC), and approximately 1 million people with HBV die from $\mathrm{HCC}$ annually. HBV is associated with socioeconomic conditions, and Southeast Asia, China and Africa have the highest rates of infection (23).

The age at which HBV infection occurs influences the long-term outcomes and determines the primary targets of vaccination programmes. Perinatal transmission from a mother to child at or soon after birth occurs in about $90 \%$ of children, with long-term complications of chronic hepatitis, cirrhosis and hepatocellular carcinoma, leading to death in middle age, particularly in men. This has serious economic consequences for both the family and country as a whole. In 1991, the Child Survival Project/Expanded Program on Immunization implemented a nationwide plan to support immunization of all infants against HBV. In the Expanded Program of Immunization, infants were vaccinated with a $2.5 \mu \mathrm{g}$ dose of a recombinant vaccine, together with a combined vaccine for diphtheria, tetanus and pertussis, at 2, 4 and 6 months of age. This recommended series of 3 intramuscular doses of the HBV vaccine induces a protective antibody response (i.e., anti-HBs antibody) in $90 \%$ of healthy adults and $95 \%$ of infants, children and adolescents (24). However, despite the introduction of successful infant and adolescent immunisation programs in many countries, the burden of HBV-related disease remains high. More than 90\% of young Egyptians have been immunised and a large proportion of older Egyptians are resistant to HBV infection because they have either been immunised or were previously infected $(4,5)$. In this study, 3 children $(9 \%)$ were positive for anti-HBs antibodies, suggesting incomplete protection against HBV infection. On the other hand, the prevalence of HBV infection among children is rapidly decreasing, with a significantly lower frequency of acute HBV infection in 2002 (5\%) than in $1983(11.9 \%)$ among those aged $12-19$ years. It is probable that the level of immunity against HBsAg is so low that anti-HBs could be diminished soon after infancy, although the HBV vaccine is useful to protect against HBV infection in early life. This may explain why the prevalence of acute HBV infection among adults aged 20-39 years was higher in $2002(20.5 \%)$, compared with the same age group in $1983(16.2 \%)$.

In this study, HBsAg was detected in 9 children (27\%). As none of the children was positive for anti-HBc-IgM, we think that these 9 children had acute-on-chronic HBV infection.
The impact of HBV vaccination in Egyptian school children aged over 10 years in an endemic area of the Nile Delta was evaluated, but the prevalence of HBsAg did not change, even among vaccinated children (25). Therefore, the high prevalence of HBsAg in vaccinated and non-vaccinated children could be due to intrauterine HBV infection, a weak immune response, or infection with escape mutant variants (25).

In this cohort of patients with symptomatic HAV, acute HBV infection was not apparent in children at 9 years of age (i.e., children who had been vaccinated), compared with an infection rate of $6.8 \%$ in the same age group at the same hospital in 1983.

In this study, seven children were negative for $\mathrm{HBsAg}$ and positive for HBV-DNA and were therefore classified as having occult HBV infection. The prevalence of occult HBV varies considerably and greatly depends on the prevalence of HBV in the general population and the methods used to detect HBV DNA (26). Occult HBV infection has been reported in patients with resolved acute-on-chronic HBV infection and in patients lacking serological markers for past HBV infection (27). Two common findings and possible explanations for occult HBV are low levels of viral replicative activity and/or mutations in the ' $\alpha$ ' epitope of the $\mathrm{S}$ gene encoding amino acid residues 100-160 of HBsAg (so-called S mutants or variants) (26). These seven children had low HBV-DNA levels, preventing us from amplifying the $\mathrm{S}$ region. The $\mathrm{S}$ gene of $\mathrm{HBV}$ has three open reading frames (i.e., the pre-S1, pre-S2 and $\mathrm{S}$ regions). The surface gene contains a neutralizing epitope, the ' $\alpha$ ' determinant region, which is located at nt 124-147. Mutations in this region could alter the antigenicity of $\mathrm{HBsAg}$, causing the failure of antiHBs to neutralize HBsAg, allowing its escape from the host's immune system, resulting in active viral replication and liver disease (28). In this study, we found no specific mutation in the ' $\alpha$ ' determinant region, such as T131I, K141E or G145R, although there were seven amino acid mutations in the pre-S and S regions in HBsAg-positive children. It is generally thought that the escape mutant is rare in Egypt. It was reported that the pre-S variant was associated with immune escape and mutations of some epitopes located downstream of the ' $\alpha$ ' determinant region might affect the neutralisation domain (29). Although the A157D and S204R variants were detected in this study, they did not affect the production of HBsAg.

HBV is classified into seven genotypes, A-G, based on sequence divergence of the entire genome of $>8 \%(30,31)$. An eighth genotype, designated $\mathrm{H}$, was recently reported in Central America (32), but it has not been fully characterised. Therefore, eight genotypes of HBV (A-H) are currently recognized and subgenotypes, differing by $\geq 4 \%$, have been described (30). A few reports have described the frequency of HBV genotypes in Egypt and revealed that HBV genotype D is the most prevalent. One explanation for this is that Egypt receives many tourists and visitors from countries where genotype D is prevalent, particularly other Mediterranean countries, with a high degree of nt homology (33). We recently reported that genotype D was prevalent among HBV carriers in Ismailia City (34). In the present study, all of the samples were classified as genotype D. A recent study showed that HBV infection exhibited some genotypic variation among children with cancer, and 
genotypes B and D were more frequently associated with malignancies than were genotypes A and C (35). Because very few studies in Egypt have focused on children with cancer, we must carefully follow-up these patients.

In conclusion, hepatitis viral infection, including acute-on-chronic infection by $\mathrm{HCV}$ and $\mathrm{HBV}$, is common among children hospitalised for acute hepatitis in Egypt. A large proportion of children were positive for HBV-DNA, possibly because of genetic variability and/or low-level immunity. Future studies should focus on improvements in immunisation programmes.

\section{Acknowledgements}

This study was supported by a Grant-in-Aid from the Japan Initiative for Global Research Network on Infectious Disease (J-GRID) supported by The Ministry of Education, Culture, Sports, Science and Technology, Japan.

\section{References}

1. Frank C, Mohamed MK, Strickland GT, et al: The role of parenteral antischistosomal therapy in the spread of hepatitis $\mathrm{C}$ virus in Egypt. Lancet 11: 887-891, 2000.

2. Sherif MM, Abou-Aita BA, Abou-Elew MH and el-Kafrawi AO: Hepatitis B virus infection in upper and lower Egypt. J Med Virol 15: 129-135, 1985.

3. El-Zayadi AR, Ibrahim EH, Badran HM, et al: Anti-HBc screening in Egyptian blood donors reduces the risk of hepatitis B virus transmission. Transfus Med 18: 55-61, 2008.

4. Zakaria S, Fouad R, Shaker O, et al: Changing patterns of acute viral hepatitis at a major urban referral center in Egypt. Clin Infect Dis 44: 30-36, 2007.

5. Meky FA, Stoszek SK, Abdel-Hamid M, et al: Active surveillance for acute viral hepatitis in rural villages in the Nile Delta. Clin Infect Dis 42: 628-633, 2006.

6. Bird BH, Githinji JW, Macharia JM, et al: Multiple virus lineages sharing recent common ancestry were associated with a Large Rift Valley fever outbreak among livestock in Kenya during 2006-2007. J Virol 82: 11152-11166, 2008

7. Ismail TF, Wasfy MO, Abdul-Rahman B, et al: Retrospective serosurvey of leptospirosis among patients with acute febrile illness and hepatitis in Egypt. Am J Trop Med Hyg 75 1085-1089, 2006.

8. Talaat M, El-Sayed N, Kandeel A, et al: Sentinel surveillance for patients with acute hepatitis in Egypt, 2001-04. East Mediterr Health J 16: 134-140, 2010.

9. Al-Aziz AM and Awad MA: Seroprevalence of hepatitis A virus antibodies among a sample of Egyptian children. East Mediterr Health J 14: 1028-1035, 2008.

10. Abe A, Inoue K, Tanaka T, et al: Quantitation of hepatitis B virus genomic DNA by real-time detection PCR. J Clin Microbiol 37: 2899-2903, 1999.

11. Yamaura T, Tanaka E, Matsumoto A, et al: A case-control study for early prediction of hepatitis $B$ e antigen seroconversion by hepatitis B virus DNA levels and mutations in the precore region and core promoter. J Med Virol 70: 545-552, 2003.

12. Sugauchi F, Mizokami M, Orito E, et al: A novel variant genotype $C$ of hepatitis B virus identified in isolates from Australian Aborigines: complete genome sequence and phylogenetic relatedness. J Gen Virol 82: 883-892, 2001.

13. Cui C, Shi J, Hui L, et al: The dominant hepatitis B virus genotype identified in Tibet is a C/D hybrid. J Gen Virol 83: 2773-2777, 2002.
14. Abdel-Hamid M, El-Daly M, Molnegren V, et al: Genetic diversity in hepatitis $\mathrm{C}$ virus in Egypt and possible association with hepatocellular carcinoma. J Gen Virol 88: 1526-1531, 2007.

15. Ohno T, Mizokami M, Wu RR, et al: New hepatitis $\mathrm{C}$ virus (HCV) genotyping system that allows for identification of $\mathrm{HCV}$ genotypes 1a, 1b, 2a, 2b, 3a, 3b, 4, 5a, and 6a. J Clin Microbiol 35: 201-207, 1997.

16. Norder H, Courouce AM, Coursaget P, et al: Genetic diversity of hepatitis B virus strains derived worldwide: genotypes, subgenotypes, and HBsAg subtypes. Intervirology 47: 289-309, 2004.

17. Saitou $N$ and Nei M: The neighbor-joining method: a new method for reconstructing phylogenetic trees. Mol Biol Evol 4: 406-425, 1987.

18. Kumar R and Agrawal B: Novel treatment options for hepatitis B virus infection. Curr Opin Investig Drugs 5: 171-178, 2004.

19. Anwar WA, Khaled HM, Amra HA, El-Nezami H and Loffredo CA: Changing pattern of hepatocellular carcinoma (HCC) and its risk factor in Egypt: possibilities for prevention. Mutat Res 659: 176-184, 2008.

20. Salama II, Samy SM, Shaaban FA, Hassanin AI and Abou Ismail LA: Seroprevalence of hepatitis A among children of different socioeconomic status in Cairo. East Mediterr Health J 13: 1256-1264, 2007.

21. Maddrey WC: Hepatitis B: an important public health issue. J Med Virol 61: 362-366, 2001.

22. Lee WM: Hepatitis B virus infection. N Engl J Med 337: 1733-1745, 1997

23. Custer B, Sullivan SD, Hazlet TK, Iloeje U, Veenstra DL and Kowdley KV: Global epidemiology of hepatitis B virus. J Clin Gastroenterol 38: 158-168, 2004.

24. Mansour E, Abdul-Rahim S, Batouty G, Zaghloul I and Abdel-Hadi S: Integration of hepatitis B immunization in the Expanded Program on Immunization of the Child Survival Project. J Egypt Public Health Assoc 68: 487-494, 1993.

25. El Sherbini A, Mohsen SA, Seleem Z, Ghany AA, Moneib A and Abaza AH: Hepatitis B virus among school children in an endemic area in Egypt over a decade: impact of hepatitis B vaccine. Am J Infect Control 34: 600-602, 2006

26. Brechot C, Thiers V, Kremsdorf D, Nalpas B, Pol S and Paterlini-Brechot P: Persistent hepatitis B virus infection in subjects without hepatitis B surface antigen: clinically significant or purely 'occult'? Hepatology 34: 194-203, 2001.

27. Carreno V, Bartolome J, Castillo I and Quiroga JA: Occult hepatitis B virus and hepatitis C virus infections. Rev Med Virol 18: 139-157, 2008.

28. Zheng X, Weinberger KM, Gehrke R, et al: Mutant hepatitis B virus surface antigens (HBsAg) are immunogenic but may have a change specificity. Virology 329: 454-464, 2004.

29. Tai PC, Suk FM, Gerlich WH, Neurath AR and Shih C: Hypermodification and immune escape of an internally deleted middle-envelope $(\mathrm{M})$ protein of frequent and predominant hepatitis B virus variants. Virology 292: 44-58, 2002.

30. Norder H, Courouce AM and Magnius LO: Complete genomes, phylogenetic relatedness, and structural proteins of six strains of the hepatitis B virus, four of which represent two new genotypes. Virology 198: 489-503, 1994.

31. Okamoto H, Tsuda F, Sakugawa H, et al: Typing hepatitis B virus by homology in nucleotide sequence: comparison of surface antigen subtypes. J Gen Virol 69: 2575-2583, 1988.

32. Arauz-Ruiz P, Norder H, Robertson BH and Magnius LO: Genotype H: a new Amerindian genotype of hepatitis B virus revealed in Central America. J Gen Virol 83: 2059-2073, 2002.

33. Saudy N, Sugauchi F, Tanaka Y, et al: Genotypes and phylogenetic characterization of hepatitis B and delta viruses in Egypt. J Med Virol 70: 529-536, 2003.

34. Youssef A, Yano Y, Utsumi T, et al: Molecular epidemiological study of hepatitis viruses in Ismailia, Egypt. Intervirol 52: 123-131, 2009.

35. Zekri AR, Hafez MM, Mohamed NI, et al: Hepatitis B virus (HBV) genotypes in Egyptian pediatric cancer patients with acute and chronic active HBV infection. Virol J 4: 74, 2007. 